\title{
P02.182. Integrative management of low back pain during pregnancy: a prospective case series
}

\author{
K Pohlman ${ }^{1 *}$, A Haan ${ }^{1}$, C Long ${ }^{1}$, T Rubley ${ }^{2}$, K Roush $^{2}$ \\ From International Research Congress on Integrative Medicine and Health 2012 \\ Portland, Oregon, USA. 15-18 May 2012
}

\section{Purpose}

Fifty to $80 \%$ of pregnant women suffer from low back pain (LBP), a condition commonly treated by doctors of chiropractic (DC). Holzer Clinic, an Appalachian integrative health facility with 140 multispecialty physicians, utilizes both conventional prenatal and chiropractic care for their pregnant patients. This study assessed the feasibility to conduct a prospective case series of LBP patients receiving concurrent conventional prenatal and chiropractic care overseen by an off-site project manager (PM).

\section{Methods}

Women age 21 and over receiving conventional prenatal care at Holzer Clinic who were referred to chiropractic care for LBP complaints were invited to participate in this IRB-approved study. The PM conducted a phone screen interview to determine eligibility. Completed baseline and 4 week questionnaires were mailed to the PM. Assessments included the Bournemouth Disability Questionnaire (BDQ), Numerical Rating Scale (NRS) for LBP, global improvement (GI) and adverse events (AE).

\section{Results}

Thirty-nine women consented to participate in the study; 17 met all eligibility criteria. Exclusions were for age, LBP before pregnancy and no DC visit. Of the 13 participants who completed both questionnaires, all were white with a mean age of 28.4 (SD 1.1) and a median gestational age of 11.0 weeks (range 2-30). After 4 weeks of care the mean GI was $72 \%$; mean improvement in BDQ was $5.8(16 \%)$; and mean improvement in pain 2.3 (SD 2.18). AEs were mild (e.g. muscle soreness of less than 48 hours).

'Palmer College of Chiropractic, Davenport, USA

Full list of author information is available at the end of the article

\section{Conclusion}

Although patient outcomes were favorable in this small study, recruitment and follow-up data collection were challenging. It is important to investigate the effectiveness of integrative care for LBP during pregnancy; however, it will require the commitment of adequate resources and collaborations.

\section{Author details}

${ }^{1}$ Palmer College of Chiropractic, Davenport, USA. ${ }^{2}$ Holzer Clinic, Gallipolis, USA.

Published: 12 June 2012

doi:10.1186/1472-6882-12-S1-P238

Cite this article as: Pohlman et al:: P02.182. Integrative management of low back pain during pregnancy: a prospective case series. $B M C$ Complementary and Alternative Medicine 2012 12(Suppl 1):P238.
Submit your next manuscript to BioMed Central and take full advantage of:

- Convenient online submission

- Thorough peer review

- No space constraints or color figure charges

- Immediate publication on acceptance

- Inclusion in PubMed, CAS, Scopus and Google Scholar

- Research which is freely available for redistribution
C Biomed Central 